\title{
IMAGINACIÓN DE INFANCIA EN MEMORIAS DE AlTAGRACIA
}

\author{
ImaGination of infancy in Memorias de AltaGraCia
}

Mónica Marinone

Universidad Nacional de Mar del Plata

Mar del Plata, Argentina

\section{Resumen}

Este artículo considera Memorias de Altagracia (1974) del venezolano Salvador Garmendia con el propósito de revisar aspectos de su escritura, en especial su modo de procesar el pasado y su configuración excéntrica de una experiencia traducida desde una perspectiva celebratoria de la infancia y el juego. El artículo también considera la importancia de dichas opciones y ciertas operaciones que permiten a Garmendia construir su particular autobiografía memorialista.

Palabras clave: Infancia, Garmendia, Experiencia, Memorias de Altagracia

\section{Abstract}

This article focuses on Memorias de Altagracia (1974) by the Venezuelan Salvador Garmendia with the purpose of reviewing aspects of his writing, his way of processing the past and his eccentric configuration of the experience that celebrates infancy and playing. This article also considers the importance of these options and operations that have helped Garmendia build his particular memorialistic-auto- biography.

Keywords: Infancy, Garmendia, Experience, Memorias de Altagracia

\section{Resumo}

O artigo foca Memorias de Altagracia (1974) do venezuelano Salvador Garmendia com o propósito de revisar aspectos de sua escrita, em especial, o modo de processar o passado e a configuração excêntrica de uma experiência, traduzida a partir de uma perspectiva que celebra a infância e do jogo. $\mathrm{O}$ artigo também considera a importância dessas opçóes e algumas operaçóes que permitem a Garmendia construir sua particular autobiografia memorialística.

Palavras-chave: infância, Garmendia, Experiência, Memorias de Altagracia

... sabemos que para efectuar la destrucción de la experiencia no se necesita en absoluto de una catástrofe

y que para ello basta perfectamente con la pacífica existencia cotidiana en una gran ciudad.

I.

La frase de Giorgio Agamben, tomada de la apertura a su Infancia e historia, por diferentes razones resulta operadora respecto de la narrativa 
de Salvador Garmendia (1928-2001). ${ }^{1}$ En un ensayo de vigencia destacable, Ángel Rama, quien leyó detenidamente a Garmendia desde mediados de los '60, lo definió como un narrador "original”, tanto en el contexto de la literatura venezolana como latinoamericana. ${ }^{2}$ Es una palabra que importa porque arrastra un peso inquietante. En su momento Rama potenció, a través de esta palabra, la atención de una crítica local poco interesada en textos "ásperos" como Los pequeños seres (el uso es de Rama), la novela de Garmendia que abre su ciclo urbano, completado en dicha década por Los habitantes, Día de ceniza y La mala vida. (Anoto que la crítica lo consideró, más tarde, el escritor que lograra universalizar la narrativa urbana de Venezuela). ${ }^{3}$ Aunque esa palabra (original) resuena respecto de relatos posteriores de Garmendia, también disruptivos, extraños en su sencillez aparente, los cuales permiten reflexiones renovadas sobre problemas complejos.

De modo directo la frase de Agamben ilumina las novelas citadas, con las diferencias de los casos y pese a la distancia temporal: como ha sido señalado por la crítica (y, es claro, Rama lo anticipa), la ciudad caótica como protagonista, la desadaptación del hombre urbano perdido, alienado en una insoportable cotidianeidad son temas que atraen a Garmendia de modo anticipado. ${ }^{4}$ Recordemos que Caracas inicia una transformación incesante a principios del s. XX, cuando se descubre petróleo, Juan V. Gómez controla el poder desde una política represiva y se imponen de manera abrupta nuevos valores que llevan al obligado reacomodo de la sociedad a una temporalidad dis-

\footnotetext{
${ }^{1}$ Salvador Garmendia nació en Barquisimeto (capital del Estado Lara) y murió en Caracas, ciudad donde residió desde 1948. Se movía cómodamente entre registros y oficios que le permitieron subsistir (fue narrador -aun de cuentos para niños, cronista, guionista y locutor de radio, guionista de televisión, teatro y cine, colaborador en periódicos, revistas humorísticas y agencias de noticias, entre otros). Obtuvo premios nacionales e internacionales (Premio Nacional de Literatura en 1973, Premio Juan Rulfo -México- en 1989 y Dos Océanos -Francia- en 1992).En 1968 aceptó un cargo en la Universidad de Los Andes, Mérida, donde dirigió una revista y la colección Actual. Desarrolló funciones diplomáticas en España (en Barcelona, ciudad que le fascinaba, antes de ser diplomático fue corresponsal). Garmendia fue director de la revista Imagen latinoamericana y propició su circulación en el continente. Algunos de sus editoriales en esta revista son destacables.

${ }^{2}$ Me refiero a "Salvador Garmendia y la narrativa informalista". En el volumen donde se incluye este extenso ensayo, citado en la bibliografía de este artículo, Rama escribe una Introducción donde detalla su anterior publicación como libro, con el mismo título, editado por la Universidad Central de Venezuela en 1975.Asimismo, en dicha Introducción indica dónde aparecieron ciertos apartados en forma de trabajos parciales, publicados por revistas especializadas, entre 1966 y 1974.
}

${ }^{3}$ Oscar Rodríguez Ortiz (18) menciona cómo son ciertos críticos latinoamericanos quienes "descubren” a Garmendia citando en particular a Rama, E. Rodríguez Monegal, J. Ruffinelli y J. G Cobo Borda. También, que La mala vida (1968) se publica por primera vez en Montevideo. Es evidente que la consagración de Garmendia llega desde afuera de su país, como a veces sucede: Uruguay,España, México, Argentina, el Caribe son zonas de circulación y recepción de sus volúmenes a través de ciertas editoriales (Arca y Seix Barral por ejemplo), en la estela de la "nueva novela" latinoamericana.

${ }^{4}$ Véase como ejemplo más cercano en el tiempo el breve ensayo de Santaella; 35 y ss. 
tinta articulada sobre la propia, que sin embargo permanece. La sumisión de la estructura estatal al capital extranjero agudiza deformaciones del imaginario social, cierta despersonalización de un colectivo drásticamente sometido a una codificación diversa. Se trata de una transformación y una pérdida de anclajes de historicidad que se precipitan desde los ' 50 , con los procesos de migración hacia centros urbanos y la sacudida demográfica que ello conlleva. ${ }^{5}$ Sin dudas, la experiencia de habitar Caracas en esa época es un un eje que Garmendia asedia obsesivamente. Aunque me parece que, si se profundiza, la indagación de la experiencia como problema explicitado por Agamben (su destrucción) o mejor, el afán (la posibilidad) de su recuperación a través de la imaginación puesta al servicio del relato como forma preferida, fue una de las preocupaciones intensas de Garmendia, y entonces el epígrafe ilumina de manera oblicua otros ejes que le permiten rondar dicho concepto -experiencia-, ejercicio que subyace o se percibe de manera intermitente en su escritura, donde el lenguaje cobra siempre protagonismo. ${ }^{6}$

II.

Él había ejecutado el más complicado de sus trucos; había salido despedido en la más arbitraria y dislocada pirueta que alguien hubiera podido imaginar y quizás todavía se encontraba girando en el aire; quizás estaba aún a tiempo para alargar el brazo y romper el hollejo del globo que lo aislaba de este lado plano del mundo y asiéndome por una mano, arrastrarme en sus vueltas, seguro de que yo le acompañaría, sin el más ligero temor, confiado en su magnífica serenidad de experto...

La cita es de Memorias de Altagracia (:48), ${ }^{7}$ el volumen que consolida una línea de fuga en la inicial tendencia urbana de Garmendia y ocupa el centro de mis reflexiones en este ensayo. En alguna entrevista describe su proceso de escritura:

Este libro aparece justamente cuando por primera vez yo me alejo del país por largo tiempo, paso un año en España y se crea esa especie de perspectiva de que siempre se habla con respecto al país y con respecto a uno mismo cuando se encuentra con una realidad que no es la nuestra y que en muchos aspectos es diametralmente distinta. ${ }^{8}$

\footnotetext{
${ }^{5}$ Cf. Rodolfo Quintero: caps. I y II.

${ }^{6} \mathrm{Mi}$ referencia a Agamben se circunscribe a ciertas consideraciones de su complejo volumen: las que vinculan experiencia con condición infante, así como la interacción imaginación/experiencia.

${ }^{7}$ Manejo la edición de Madrid: Cátedra, 1982. Las citas y paginación anotadas corresponden a esta edición. En citas abrevio MA.

${ }^{8}$ Declaraciones a Gabriel Jiménez Emán. Citado en Salvador Garmendia: 1989.
} 
Memorias... se produce "de corrido" (ORTIZ, 1982: 27) y es publicado por Seix Barral (Barcelona) en 1974, edición que propicia su circulación en contextos hispanohablantes. ${ }^{9}$ Es ejemplo magistral de su estética reivindicatoria de la intimidad, de mundos cotidianos a veces alucinados e "irreales", así como de su trabajo con la materialidad del lenguaje en beneficio de la interferencia, la contaminación de planos o la disolución de límites (aun del que nuestra condición de lectores -ajenos- impone). También de su valoración de la consistencia del cuento y de lo breve como lo intenso, una brevedad que en Hace mal tiempo afuera por ejemplo, volumen de circulación escasa, llega a puntos de exaltación máxima. Son modulaciones que a la par redundan en la ambigüedad desde una escritura que, en su forma misma, propicia la salida de precisos (cómodos) lugares de lectura e interpretación porque descomponen la armadura de lo establecido.

La ambigüedad cristaliza desde las primeras opciones de Garmendia, como la disposición organizativa de Memorias de Altagracia: es una sucesión de dieciocho relatos sin título ni numeración, que nos instalan en un universo provinciano, donde la cronología está quebrada, detenida; dichos relatos entran en diálogo o se integran en una totalidad, aunque a su vez son unitarios. Así, Garmendia libera la decisión del corte de lectura o de su prosecución a partir de cualquier lugar, y en trasfondo revela una concepción de la escritura como continuum que siempre admite más, que podría proseguir sin perjuicio del resto. En las contratapas de las distintas ediciones suelen categorizarlo como volumen de cuentos; el tipo de entramado permitiría definirlo también como novela memorialista. Salvador juega con estas posibilidades y sutilmente nos ingresa, desde el primer contacto, en un terreno inestable en el sentido de la no - fijación, de una ausencia de control que refuerzan tanto la falta de explicaciones como de un orden sometido a parámetros habituales. La cita con que abro este apartado corresponde al primer relato de Memorias...; se integra en un fragmento donde Garmendia cuenta la muerte del tío Gilberto por boca de su narrador. Gilberto es el boticario, un personaje entrañable que cobra peso nada casualmente en inicios del volumen porque instaura el juego como código comunicacional (con dicho narrador, con los lectores), un juego que incluye hasta un lenguaje compartido y de engańoso sin-sentido (“-Cachún capú de molenín-me decía en nuestro idioma...” MA: 44. Subrayado mío).

\footnotetext{
${ }_{9}^{9}$ Memorias de Altagracia fue el primer volumen de Salvador Garmendia que,a inicios de los '90, llegó a mis manos en la edición de Seix Barral de 1979 y sobre el cual escribí de inmediato (Cf. MARINONE, 1993). Accedí al resto de su narrativa por generosidad del mismo Salvador, de amigos y colegas de Venezuela o por compra directa en ese país. La mención importa en aras de revisar modos de circulación de textos latinoamericanos en este continente entre los '70 y fines de los ' 90 , a veces menos estimulados que en USA o Europa.
} 
Si esta organización propicia el desacomodo entendido como la salida del lector de un lugar preciso, debo decir que el proceso se inicia antes, con la elección del título, ese umbral (del arco comunicativo) que prepara para lo por venir. La palabra "memorias" instaura cierto pacto de lectura que tiende a suspenderse cuando se cae en la cuenta de que el texto está sometido, en su mayor parte, a la perspectiva de un niño. Recordemos que, en líneas generales, las memorias son producidas por hombres para generar grandes hombres, siendo un registro donde se funden el recuerdo de la historia subjetiva y su verdad psíquica con el recuerdo de la Historia y su verdad histórica. ${ }^{10}$ Conviene señalar que el uso perspectiva (Rodríguez Ortiz la llama "lente de la infancia": 29) dialoga cómodamente con el concepto de experiencia con que he iniciado este ensayo. Memorias de Altagracia no es la efectuación de una escritura en la infancia desde un saber reflexivo acerca de dicha infancia: dice con precisión N. Rosa (:57) que "un infante no puede escribir la infancia porque no sabe nada de la infancia”. La apuesta de Garmendia (e insisto en la importancia de la cita con que inauguro este apartado pues pone en escena su ejercicio) es la voluntad de recuperar un modo de percepción ligado a los afectos y al cuerpo como forma de traducir experiencia (lo destruido según Agamben). Es una voluntad esforzada en desactivar -lo más posible- la intermediación reflexiva que suponen tanto el recordar escenas y momentos de la infancia como, en grado sumo, el acto de escribir dicho recordar. Intento explicar que en Memorias..., aun vislumbrándose esa intermediación en ciertas divergencias o desfases que algunas palabras y, especialmente, ciertos verbos suponen (me refiero a divergencias temporales y entonces de identidad, que implican la reflexión y el acto de escritura), ello termina siendo olvidado porque las operaciones de Garmendia lo sofocan.

Me parece que este volumen es un punto de fuga en el universo narrativo del venezolano no solo porque se desprende de la ciudad, sino porque es una exploración narrativa notable desde el prisma de una mirada infantil que recupera y revela el carácter "transubjetivo" de experiencias iniciales, "que no disocian el sentimiento de sí del sentimiento del otro" (GUATTARI, 1996: 17), y agregaría, de lo otro. Desde el ensayo de Agamben (:16) y sus planteos, la propuesta de Garmendia remitiría a la Antigüedad, cuando "el problema central del conocimiento no (era) la relación entre un sujeto y un objeto, sino la relación entre lo uno y lo múltiple”. En esta línea interpretativa y recuperando a Guattari para abonarla, completo mi definición de Memorias de Altagracia apelando a la noción decartografía, una puesta material (la escritura es una materialidad) de puntos de referencia cognitivos, de rituales,

\footnotetext{
${ }^{10}$ Sigo a ROSA, 1990: 55.
} 
vínculos compartibles y no compartibles, costumbres orgánicas... fijados en alguien (en cualquiera), los que, inscriptos en dicha subjetividad en estado infante, son fundacionales y por esto llevarían la marca de lo recurrente, de lo que puede reaparecer (como dice Guattari fundado en Stern: $17^{11}$ ) en el sueño, el delirio, la exaltación creadora o el sentimiento amoroso. Y si Agamben (25) advierte sobre la enorme dificultad o la situación paradójica en que se encuentra quien se proponga recuperar una experiencia tradicional, me parece que Garmendia asume el reto apoyado en dos variables de distinto orden, que sin dudas viabilizan su proyecto: la infancia y la imaginación.

III.

Infancia e imaginación, como puede suponerse, son variables que dialogan cómodamente respecto de un contexto epocal previo (y no me refiero a la Antigüedad, sino a la infancia del mismo Garmendia, no tan alejada, hoy, de la de muchos), contexto que, obviamente, no es el contemporáneo, cuando las experiencias de infancia han "mutado". Y aquí es de utilidad apuntar juicios de A. Baricco, quien, como Agamben, se ve atravesado por Walter Benjamin en su intento -más acotado- de definir la experiencia y de trazar ciertas comparaciones que involucran modalidades contemporáneas, las que, provocativamente, incluye en sus ensayos sobre la mutación (de ahí mi uso). En realidad me interesa adelantar su modo de concebir experiencias de otro tiempo desde un fragmento productivo para Memorias de Altagracia, que hacia el final de este ensayo cobrará énfasis:

La experiencia en su sentido más elevado y salvífico, estaba relacionada con la capacidad de acercarse a las cosas, una a una, y de madurar una intimidad con ellas capaz de abrir las habitaciones más escondidas. A menudo era un trabajo de paciencia, y hasta de erudición, de estudio. Pero también podía ocurrir la magia de un instante, en la intuición relámpago que llegaba hasta lo más hondo y traía a casa el ícono de un sentido, de una vivencia efectivamente acaecida, de una intensidad del vivir.... se trataba de un asunto casi intimo... (114). Subrayados míos.

Podrían referirse muchos ejemplos de la literatura sobre maneras de actualizar estas descripciones de Baricco (desde Proust en adelante), aun consideradas las variables que nos ocupan, pero pretendo concentrarme en Garmendia. Como ha sido estudiado por teóricos y críticos, la imaginación conlleva un enorme poder, aunque ha subsistido y aún subsiste el impulso de expulsarla del dominio del conocimiento. Precisamente Agamben (25) se

\footnotetext{
${ }^{11}$ La referencia de Guattari (17)es: D. Stern, The Interpersonal World of the Infant. NY: Basic Books: 1985.
} 
detiene en su identificación como médium por excelencia, una valoración inherente a la antigüedad. Dice (ibid.): "Lejos de ser algo irreal, el mundusimaginabilistiene su plena realidad entre el mundos sensibilisy el mundusintelligibilis". En la cita de Memorias... con que abro el apartado II, que cuenta la muerte de Gilberto, los tres mundusse imbrican para potenciarse y "vislumbrar" (como modo de traducir) la experiencia de un límite entre esferas (lo físico- lo metafísico/ lo uno- lo múltiple/ saber humano -saber divino/ este lado-otro lado, etc.) Son "esferas" separadas por un límite "inexperimentable" como la muerte (dos conceptos de Agamben (:16) en su revisión de Montaigne). Pero desde el prisma del infante de Garmendia, quien apela a la esfera desde ciertos usos ("girando", "globo", "vueltas"), se traduce en experiencia de un límite que el juego como código comunicativo "quizás" pueda disolver, un límite al que dicho infante sin dudas se aproxima y pretende atravesar confiadamente, sin temores, que entonces (nos) resulta exento de dramatismo porque está mediado por dicho el juego ("el más complicado desus trucos" dice, y sigue: “... quizás estaba aún a tiempo para alargar el brazo y romper el hollejo del globo que lo aislaba de este lado plano del mundo y asiéndome por una mano, arrastrarme en sus vueltas, seguro de que yo le acompanaría...”. Subrayados míos). Sin dudas Garmendia parece afiliarse a las recomendaciones de Montaigne: "acostumbrarse" y "quitarle su extrañeza" a la muerte (AGAMBEN, 2007: 16).

A propósito, una de las virtudes que conlleva la plena realización de las operaciones de Garmendia es que, a pesar del indicio personal constante, el "yo" está decolorado, diluido en una totalidad que se aprehende, borrado como individualidad hasta el punto de la prescindencia de un nombre que lo identifique. $Y$ desde aquí regreso al pacto de lectura que el título propone y a su reactivación, a la pertinencia del uso "memorias" anticipando un ejercicio dirigido al exterior y no a una exploración interior que más bien se torna instauración de una subjetividad entremezcla con dicho exterior, tal como indiqué. Entonces, el título prefija el protagonismo de Altagracia (pese a uso de la subordinación "de Altagracia”) y esta mención, desde inicios, tensa la fundación de esa subjetividad, que, como corresponde también a las "memorias" y a pesar de la decoloración referida, no vacila. ${ }^{12}$

En este sentido vale anotar que la perspectiva desde un $y o$, como ha sido harto estudiado por la Lingüística para los pronombres personales y Agamben (:63) se encarga de recordar en su ensayo, “... se refiere al acto de discurso individual en que es pronunciado... (y) no puede ser identificado sino en una instancia de discurso". De ahí que se alce como una operatoria (una virtud dije) que conlleva otros efectos: además del protagonismo de Altagracia exterior al

12 Sigo a ROSA, 1990: 56. 
yo que por la perspectiva asumida es un foco poderoso del volumen, y de la pertinencia del uso Memorias aún desde la perspectiva infantil, considerados los lectores pienso en el refuerzo de un arco de complicidad. Las primeras ediciones también la ponen en escena. Cuando Seix Barral publica este volumen, no incluye datos o explicaciones que abunden en la biografía de Salvador Garmendia, quien aparece entonces diluido (como el yo que controla el enunciado) en tanto no necesariamente vinculable con el niño que, en general, controla el enunciado. Es Altagracia la palabra convocante (quien no conoce de geografía venezolana y se entrega al relato, no necesariamente identifica este nombre con un lugar de sus características). Después, las diferentes reediciones (Cf. Cátedra) incluyen estudios preliminares e introducciones que modifican la propuesta inicial. Me parece que las pretensiones originarias de Garmendia fueron inducir a la ambigüedad desde su misma borradura como sujeto (o foco) de las experiencias vertidas (la intención de borradura fue un gesto frecuente de los escritores latinoamericanos, especialmente desde los '60 y aún antes), no preparar al lector respecto de aproximaciones auto-bio-gráficas -a las que recurren las ediciones de Memorias... posteriores a los '70- hacia el desconcierto y el desacomodo. Pero también propiciar el acercamiento a ese yo, una compenetración cuya "realidad", por ser discursiva es reactualizada (presentizada) en cada acto (individual) de lectura. Este argumento dialoga con el resto de sus operaciones, algunas de las cuales he descripto.

IV.

Mi elección de la palabra "cartografía" para definir Memorias de Altagracia no es arbitraria. Aquí la memoria es claramente una facultad, pero también un sitio restituido o puro lugar de acumulación, como la escritura. Ha sido planteado claramente por Bachelard (: 39-40) que "...la memoria no registra la duración concreta, el tiempo no la anima...”, que “...es en el espacio donde encontramos (los) bellos fósiles de duración...”, y que “...para el conocimiento (agregaría, por mi parte, para la experiencia) de la intimidad es más urgente que la determinación de las fechas, la localización... en los espacios". En Memorias de Altagracia dichos planteos se cumplen y el espacio parece teñirlo todo de manera directa o sesgada, comprometiendo otros planos: el tiempo es espacio ${ }^{13}$ y los seres también pueden serlo, ${ }^{14}$ de ahí la necesidad de pensar dicha categoría en un sentido lo más amplio posible.

${ }^{13}$ El tiempo, una aporía, siempre se describe desde marcas espaciales, pero Garmendia lo explora y estiliza: "Los días... adquieren una rotación concéntrica y pueden fragmentarse en numerosos remolinos cuyosvértices llegan a hacerse inalcanzables..." (MA: 41)

${ }^{14}$ Algún personaje contiene partes invisibles que, sin embargo, resonarían si se lo sacudiera (Cf. Adelmo); otros, como "las mujeres largas de la lluvia", pueden ser invadidos: "Ella no iba a hacer 
Como es de presumir, la casa es el primer centro que Garmendia funda en su cartografía desde el prisma del yo/niño. Lo instaura en la apertura de Memorias..., de modo tal que, en palabras de Bachelard, adquiere el peso de un "núcleo de fuerza" que ilumina y opera. Un fragmento inolvidable lo configura, de manera natural, como algo vivo:

... la casa comienza a ensancharse por todos lados. Aquel cuerpo grande y lastimado se cubre de pálpitos y manifiesta los más angustiados síntomas de vida. Es posible que en cualquier momento pretenda enderezarse en un esfuerzo retardado de animal renco, encogiendo las articulaciones secas, estirando los huesos y las viejas carnes arrugadas. Se le ven salir brazos por los lados, cavidades largas y oscuras donde el polvo que cubre las maderas es una capa tierna como las orlas de un traje..." (MA: 41)

En este sentido, la analogía lingüística entre el ensayo de Bachelard (1957) y el volumen de Garmendia respecto de la definición-descripción de la casa es notable: el ensayo, de corte hermenéutico, parece sustentar teóricamente las operaciones de Garmendia, que, es claro, sumergen en el juego estético propiciando nuestra aprehensión profunda. En inicios del Capítulo I titulado "La casa", Bachelard la denomina "un ser privilegiado" (: 33) y más adelante, "cuerpo y alma” (: 37). Son frases que reenvían al fragmento de Garmendia, donde la animización es mucho más que un procedimiento: es la operatoria nodal que apoya la interferencia entre órdenes (y categorías) que he anticipado como constante del volumen. En relación, observemos que la cita rebosa nominalmente, y solo dos sustantivos podrían atribuirse, de manera estricta aunque no exclusiva, al dominio espacial: polvo y madera. El resto redunda en la animalización, y se connota de un tiempo antiguo, viejo.

Es el principio de un movimiento que es el despertar de la casa (así como del recuerdo y de la escritura de un recuerdo que no parece tal por el uso de un tiempo presente que produce el efecto de algo continuo). Anticipa, en el inicio del volumen, el carácter operador del primer centro de esta cartografía. Por ello la casa, como Bachelard (: 36) explica en el capítulo I y Garmendia ratifica, es un núcleo de fuerza que se arrastra siempre en tanto poder de integración "para los pensamientos, los recuerdos y los sueños":

También se puede llevar por la calle toda la casa con sus ruidos, las caras distraídas que parecen ir de viaje a lugares de mucha gente donde hay gritos y música, el patio encandilado lleno de ponzoñas y hojas velluda, el susto en una ventana entreabierta y levarla así, del diestro, como un caballo grande y huesudo. (MA: 42)

el menor movimiento y se dejaba atravesar por el medio tal como si me lanzara dentro de una oscuridad sin fin..." (MA: 73) 
En este fragmento Garmendia juega con los dominios espacial (en apertura) y animal (en cierre) desde la apelación a lo frecuente, la comparación ("como un caballo grande y huesudo") donde el término B (caballo) se explicita e ilumina la cita previa (solo orientada a la animización): así refiere esta posibilidad de arrastre que describe (fenomenológicamente) la experiencia de habitar la casa, primer universo o primera intimidad que siempre se porta (llevar dice Garmendia dos veces).

El segundo centro de esta cartografía es precisamente Altagracia, ${ }^{15}$ sus calles, la botica, el estudio del fotógrafo, los trenes, la plaza...: se trata del reducido espacio provinciano, estable y tranquilizador, con casas de habitaciones enigmáticas y cuartos para el loco de la familia. Altagracia ingresa a cuentagotas y de modo oblicuo pues se entrevera con personajes, a veces desopilantes, que también son hitos de esta cartografía. Desde dicho ingreso se alza, a trasluz, una temporalidad (la experiencia de un tiempo) sujeta al ritmo cotidiano del interior provinciano, diría una experiencia contemplativa, ajena al vértigo de la ciudad subordinada a la producción/transformación. La experiencia del tiempo de Altagracia es como la tendencia que el volumen impone en general obligando al reacomodo lector: detenida, signada por la duración:

El tallercito de fotografía está siempre tan lleno de humedad como un traje de pańogrueso que hubiera sido abandonado mucho tiempo a las lluvias. Es un baúl de viejo, lleno hasta los topes, enterrado bajo el nivel de la calle que a su vez llega a ser una calle de enanos, donde las caras cubren todo el hueco de las ventanas, que figuran marcos de retratos torcidos y negros y los hombres vestidos de dril cruzan haciendo reverencias por las puertas más pequeñas del mundo y al dar un paso se disuelven por completo en lo oscuro. (MA: 61)

Si el tiempo y los personajes son objetos continentes, los espacios mayores, en este caso un tallercito,es como un traje o un baúl de viejo. Es hora de decir que todas las citas insertadas en este ensayo -ya en cuerpo, ya en notasrevelan el trabajo detenido sobre el lenguaje: desde la elección de las palabras a la manera como se configuran las descripciones, esto es, al vigor otorgado a la descripción como la mayor posibilidad, profunda y abarcadora, cuando se pretende instaurar un pensado proceso de atracción y disolución de nuestra distancia. En el último fragmento es claro el afán de "mostrar" (describir no es analizar ni explicar) desde una perspectiva infantil por la cual el disparate o el peso de lo desopilante a que me referí antes, no son tales. Es decir, no suponen nunca una discontinuidad semántica, sino una manera de traducir experiencia, de ahí que Garmendia explote hasta la exacerbación la descripción de percepciones abonando con comodidad este prisma desde modulacio-

\footnotetext{
${ }^{15}$ Rodríguez Ortiz explica: "Altagracia está en Barquisimeto... (también) "se nombran poblaciones vecinas: El Tocuyo, Yaritagua.... Se componen, sin embargo, de una unidad solidaria...” (: 27-28)
} 
nes que no reclaman verosímil o ajustes a una racionalidad convencional. La descripción de percepciones y la discontinuidad que lo fragmentario da, contribuyen en Memorias... a romper con presupuestos como causalidad y sentido final, es decir, a la razonabilidad tranquilizadora del pensar. Garmendia descree de esos velos (causalidad y finalidad) cuestionados ya por Nietzsche, que cubren con la apariencia de un orden conveniente, y asume una perspectiva infantil (infancia e imaginación asociadas) que inhabilita dudas porque su narrativa se vuelve creíble en tanto ficción, como diría Saer, ${ }^{16}$ propiciando una lectura liberada de prejuicios y a su vez, sosegada.

V.

Cerca de la piel verde de ese estanque, que se arruga de nada más soplar por encima, la cara de uno que nunca llega a hundirse más allá de donde se puede tocar con los dedos, es una telita delgada de agua sólida que hace ondas o se deshace por los lados, o se destruye por completo en trozos desunidos o trémulos entre los cuales se suceden visiones repentinas de ojos y pedazos de piel que intentan reunirse muchas veces y se despegan nuevamente acometidas por innumerables reflejos; hasta que la figura se rehace por sí sola. (MA: 17)

Como ha estudiado Merleau Ponty, el campo perceptivo está lleno de reflejos, crujidos, impresiones táctiles fugaces, por eso algunos seres, algunos objetos, ciertos momentos se nos dan desde un universo de datos, con la extremada precisión de los detalles y al mismo tiempo, como un todo indivisible, antes de cualquier juicio. La cita con que abro este apartado es ejemplar respecto de esta explicación, de cómo en Memorias de Altagracia, el trabajo sobre el lenguaje configura el como si de la percepción (traduce la experiencia), o el proceso por el cual se integran impresiones sensoriales, por ejemplo sobre personajes (las mujeres largas de la lluvia), objetos (el estanque) o acontecimientos (la circulación de los trenes) donde los detalles y el todo se imbrican. Entonces la forma, el movimiento, el color o el sonido, aun de lo mínimo, surgen en el acto de lectura, con un sentido inmanente, tal como se presentarían a nuestros sentidos. ${ }^{17}$ Regreso a la realización de Memorias... y de ciertos efectos pretendidos: la lectura sosegada, impulsada indefectiblemente por la descripción (en particular, por la descripción de percepciones) $y$ un acercamiento o instalación en un tiempo que es presente (la percep-

${ }^{16}$ Dice Saer (2): "Pero la ficción no solicita ser creída en tanto que verdad sino en tanto que ficción. Ese deseo no es capricho de artista, sino la condición primera de su existencia, porque sólo siendo aceptada en tanto que tal, se comprenderá que la ficción no es la exposición novelada de tal o cual ideología, sino un tratamiento específico del mundo, inseparable de lo que trata”. En el caso de esta narrativa de Garmendia, pese a la dificultad que suponen sus elecciones e intereses, el juicio de Saer se cumple sobradamente.

${ }^{17}$ Sigo a Merleau Ponty. 
ción es conocimiento del presente) y contribuye a la unidad del yo en un ser / estar. Como ha sido señalado, el infante cultiva esta unidad en su manera de producir experiencias, manera analógica a su posibilidad de in-disociar el sentimiento de sí del sentimiento del otro o de lo otro según anticipamos, o carácter transubjetivo de estas experiencias iniciales. Se puede apreciar que es un lenguaje afanado en trabajar la borradura de límites en toda la red textual desde quiebras semánticas que dan notable densidad al discurso: en la última cita, espacio y personaje se entrelazan desde imágenes visuales, táctiles y de movimiento mínimo, propiciando la disolución de uno en otro. ${ }^{18}$

De este modo, todos los planos son homologados y ningún orden se jerarquiza respecto de otros. Y si laexperiencia de la muerte de Gilberto se mediatiza por el juego y la imaginación, lo mismo sucede con las acciones de las películas que el niño ve o las que involucran una tradición o un pasado heroico escuchado en relatos de otros, que ingresan con el mismo estatuto. Así, todo cobra la misma consistencia, desde los sueños, propios y ajenos, a los inventos del mecánico o las herramientas del castrador de chivos. Pero lo inquietante es el efecto de naturalidad induciendo esa vocación de intimidad que la cuestión y la perspectiva infantil elegidas instalan. Es una naturalidad que se configura en el comienzo de cada parte de Memorias..., una de las mayores dificultades que entraña el acto de escritura. El saber de los comienzos que vislumbro en los textos de Salvador Garmendia sería esa competencia por la que pareciera no haber preparación o reorganización de una carga previa, como si ese imaginario acumulado a que se refiere Jitrik en Los grados de la escritura (:93) respecto de "empezar a escribir", un imaginario que está saturándose constantemente, no pesara, no planteara una inminencia. O como si la escritura en tanto acto físico y continuum no sólo descansara en esa red, sino que le fuera inherente, es decir, fuera la instancia de un previo librado de conflicto y de hiatos que prevé lo que sigue. Me parece que aquí reside el principio de ese efecto de naturalidad que otras estrategias orientan en cada desarrollo: en la posibilidad de unos comienzos como zonas que parecieran restituir un diálogo sólo suspendido en apariencia, cuya particularidad, por lo contrario, sería la pura continuación.

He leído repetidas veces la extensa dedicatoria que abre Hace mal tiempo afuera. Salvador hablaba de este volumen como de un regalo para los amigos, para sus afectos, seres puntualmente indicados en inicio de cada relato. Me he preguntado, también repetidas veces, por qué esa extensa dedicatoria a su hermano me resulta un texto operador: se trata de una vasta enumera-

\footnotetext{
${ }^{18}$ Me refiero a "piel verde", "se arruga", "la cara de uno... telita delgada de agua sólida que hace ondas o se deshace por los lados, o se destruye por completo en trozos".
} 
ción de objetos, de imágenes sensoriales, de impresiones, nada extravagantes porque, se entiende, son propios de un espacio íntimo compartido, sencillamente próximas, congruentes. Sin embargo este encuentro tan poco desconcertante posee para mí, un "poder de encantamiento", ${ }^{19}$ la fuerza seductora de una primera escena textual (aquí el comienzo es la dedicatoria). Quizás sea porque a través de la feliz acumulación nominal como simple nombrar, Salvador logra restituir la vitalidad de un tiempo, el intenso modo de haberlo vivido. Y me parece que por esto Garmendia también logra lo que Rama (: 169) señala como efecto convocante: "Leyendo a Salvador Garmendia he pensado muchas veces que él arrastra una memoria ancestral, que más que la suya individual... es la memoria de la especie."

Las dos frases que enmarcan la dedicatoria quizás contribuyan a este poder y de algún modo refuerzan el peso discursivo del fragmento, que vale la pena transcribir:

Para mi hermano Hermann Garmendia, en nombre del piano de la sala, la ventana de reja, el mecedor, el gran espejo carcomido y las manchas de tinta en la mesa de mármol; el tinajón del patio, la mata del jazmín del cabo, el crujido de la cáscara de tamarindo dulce; el olivo, el cristal de la sábila, la pestilencia de la cola rancia en el cuarto de encuadernación, el jugo de la verdolaga, la baba del caujaro, el sabor del clavel del muerto; un volumen en cuarto de $L a$ Isla Misteriosa de Julio Verne con todas sus páginas remendadas, el vientre de Mateo Mole y las lágrimas de Guido de Fongalan derramadas en vano; la piedra del fogón de leña; la piedra de los alińos, la piedra de moler maíz; el crujido de la cuerda del reloj de péndulo, las dos alacenas del comedor, los dobles de las seis de la tarde. Para Hermann, en fin, donde comenzó todo.

Sin dudas, este fragmento revela, líricamente, lo que anticipé desde la cita de Baricco que reitero en parte: "la capacidad de acercarse a las cosas, una a una, y de madurar una intimidad con ellas capaz de abrir las habitaciones más escondidas... un trabajo de paciencia". Quiero permanecer en el efecto de dicho "episodio"de lenguaje que traduce experiencia sin explicar, y en la frase final ("donde comenzó todo") como marca susceptible en su implicar un principio y un universo mayor, el de Memorias de Altagracia. Los leo como centros de energía de su escritura, actos generadores que, en la posibilidad de constitución de una pertenencia, de un sujeto en su recordar la niñez desde imágenes y sinestesias, es decir, esas interferencias de sensaciones que los diferentes sentidos a veces propician en un mismo acto perceptivo y aquí traman la materialidad del lenguaje, traen un mundo antiguo que al ser traducido (en lenguaje) a la parcuenta, constituyéndolo cada vez, para siempre.

\footnotetext{
${ }^{19}$ La expresión es de Foucault respecto del efecto que la enumeración de Borges le producía, justamente por razones opuestas.
} 
Bibliografía citada

AGAMBEN, Giorgio. Infancia e historia. Destrucción de la experiencia y origen de la historia. Buenos Aires: Adriana Hidalgo Editora, 2007.

BACHELARD, Gastón. La poética del espacio. México: FCE, 1974.

BARICCO, Alessandro. Los bárbaros. Ensayos sobre la mutación. Barcelona: Anagrama, 2006.

FOUCAULT, Michel. Las palabras y las cosas. Barcelona: Planeta, 1984.

GARMENDIA, Salvador. Hace mal tiempo afuera. Caracas: Fundarte, 1986.

GUATTARI, Félix. Caosmosis. Buenos Aires: Manantial, 1996.

JITRIK, Noé. Los grados de la escritura. Bs As: Manantial, 2000.

MARINONE, Mónica. "Salvador Garmendia: entre el juego y las memorias”, Cuadernos para la investigación de la Literatura Hispánica, Madrid, n. 17, 1993: 143-162.

MERLEAU PONTY, Maurice. Fenomenología de la percepción. México: FCE, 1957.

QUINTERO, Rodolfo. Antropología del petróleo. México: Siglo XXI, 1972.

RAMA, Ángel. "Salvador Garmendia y la narrativa informalista”. En Ensayos sobre literaturavenezolana. Caracas: Monte Ávila, 1991: 99-219.

RODRÍGUEZ ORTIZ, Oscar. "Introducción”. In: GARMENDIA, Salvador. Memorias de Altagracia. Madrid: Cátedra, 1982: 9-33.

ROSA, Nicolás. El arte del olvido. Buenos Aires: Puntosur, 1990.

SAER, Juan J. "El concepto de ficción”, Punto de vista. Año XIV, n. 40, 1991: 1-3.

SANTAELLA, Juan Carlos, "Tiempo y novela en la obra narrativa de Salvador Garmendia”, Actual, Venezuela, n. 49, 2003: 35-42. (Dossier Salvador Garmendia).

Mónica Marinone é professora e pesquisadora do CELEHIS /Facultad de Humanidades, Universidad Nacional de Mar del Plata. Autora de Escribir novelas. Fundar naciones, de Rómulo Gallegos. Imaginario de Nación e coautora de La reinvención de la memoria, Senderos en el bosque de palabras, Escrituras y exilios en América Latina. Coordenadora de três volumes internacionais sobre Latinoamérica: Grabar lo que se desvanece. Narrativas de la memoria en América Latina; Viaje y relato en Latinoamérica, y Noticias del Diluvio. Textos latinoamericanos de la última década. Responsável pela organização de antologias e autora de diversos ensaios em livros e revistas especializadas.mmarinone@gmail.com 